\title{
As dimensões da Educação do Campo ${ }^{1}$
}

\author{
Dimensions of Rural Education
}

\section{Edna Maria Querido de Oliveira Chamon* \\ Universidade de Taubaté}

Resumo A Educação do Campo, como parte de um projeto contra-hegemônico de sociedade, vai além de sua versão escolarizada, colocando-se na contramão da lógica capitalista. Sua proposta incorpora as dimensões política, social e cultural, além da própria dimensão pedagógica. Este artigo discute três dessas dimensões: epistemológica, sociológica e formativa, e as articulações entre elas. Em sua dimensão epistemológica, a Educação do Campo contesta a instrumentalização capitalista da ciência; no plano sociológico, opõe-se à exclusão da cultura e do conhecimento dos sujeitos do campo imposta dissimuladamente pela classe dominante; e, do ponto de vista da formação, afirma o trabalho como princípio educativo. Ela sustenta o direito dos povos do campo a pensar e a definir a educação a partir de seu lugar, de sua cultura e de suas necessidades.

PALAVRAS-CHAVE: Educação do Campo; Formação e trabalho; Discurso educacional.

Abstract The Rural Education, as part of a counter-hegemonic project of society, goes beyond its school version by fighting against the capitalist logic. Its proposal incorporates political, social, and cultural dimensions, in addition to the pedagogical dimension. This article discusses three of these dimensions: epistemological, sociological and formative, and their articulations. In its epistemological dimension, the Rural Education challenges the capitalist exploitation of science; on the sociological level, it opposes the exclusion of culture and knowledge of the rural people covertly imposed by the dominant class; and from the formative point of view, it promotes the work as an educational principle. It supports the right of rural people to think and to define education from their place, their culture and their needs.

KEYWORDS: Rural Education; Education and work; Educational discourse. 


\section{Introdução}

O Brasil, há já algum tempo, é anunciado como uma economia do conhecimento da natureza (BOUND, 2008), na qual conhecimento científico, tecnologia, recursos naturais e meio ambiente convergem para uma nova forma de desenvolvimento. As propostas do capital, como sistema hegemônico, apontam para uma educação instrumental que permita a exploração capitalista desse conhecimento da natureza. Uma proposta contra-hegemônica aponta para o conhecimento e a transformação da natureza para o bem-estar do ser humano.

Assim, o debate educativo para o campo não pode ser, e não é, política e ideologicamente neutro, visto que vai representar uma dessas propostas. A busca de uma educação libertadora, voltada para a totalidade do ser humano, implica necessariamente que os conceitos capitalistas de eficiência e produtividade devam ser rejeitados como base para uma Educação do Campo.

Por outro lado, o acesso à cultura construída historicamente pela humanidade, hoje restrito a uma minoria, não pode ser desconsiderado e deve ser reapropriado pelas classes trabalhadoras. Por outros meios, para outros fins, em outro contexto. Mas deve ser universalizado.

Ao mesmo tempo, segundo dados do Instituto Nacional de Colonização e Reforma Agrária - INCRA, há mais de seis milhões e meio de jovens e adultos analfabetos no meio rural brasileiro. A isso, acrescenta-se o fato de que dois terços dos assentados em áreas de reforma agrária são analfabetos funcionais (SILVA; COSTA; ROSA, 2011).

Como diria Bourdieu (apud BAUMAN, 2009, p. 189), "para conceber um projeto revolucionário, quer dizer, uma ambição pensada de transformar o presente por referência a um futuro projetado, é preciso ter um mínimo de controle sobre o presente". A educação, em particular a Educação do Campo, deve ser pensada como um caminho para se obter esse controle sobre o presente. Esse caminho passa pela aquisição do conhecimento já consolidado; pelo conhecimento prático e tradicional já construído pelo trabalhador do campo; e, pela articulação desses dois pólos, que pode ser vista como a contextualização do conhecimento a partir do campo e com a participação do campo.

Esses pontos já estão reconhecidos nas Diretrizes Operacionais para a Educação Básica nas Escolas do Campo que definem a Educação do Campo

[...] pela sua vinculação às questões inerentes a sua realidade, ancorando-se na temporalidade e saberes próprios dos estudantes, na memória coletiva que sinaliza futuros, na rede de ciência e tecnologia disponível na sociedade e nos movimentos sociais em defesa de projetos que associem as soluções exigidas por essas questões à qualidade social da vida coletiva no País. (BRASIL, 2002, p. 37).

Da mesma forma, o Plano Nacional de Educação (BRASIL, 2014) já prevê o estabelecimento de estratégias que "[...] considerem as necessidades específicas 
das populações do campo e das comunidades indígenas e quilombolas, asseguradas a equidade educacional e a diversidade cultural", apontando para as especificidades da Educação do Campo.

A Educação do Campo é, portanto, a manifestação de um projeto de sociedade, voltada para o equilíbrio entre o bem-estar humano e a preservação da natureza.

Estando associada a esse projeto de sociedade, a Educação do Campo vai muito além de sua versão escolarizada e, seguramente, na contramão da lógica capitalista dominante. Sua proposta incorpora muitas dimensões - política, social, cultural - além da própria dimensão pedagógica que lhe é própria.

Este artigo propõe discutir algumas dessas dimensões e as formas como elas se articulam, representando um novo discurso e uma nova voz para o campo. Nessa linha, o artigo repassa rapidamente a construção de uma Educação do Campo contraposta à Educação Rural e avança na discussão de algumas de suas dimensões: epistemológica, sociológica e formativa. Transversal a essas dimensões e fundamento para elas é a perspectiva dos povos do campo como sujeitos - pedagógicos, históricos, políticos-, enfim, sujeitos produtores de existência e conhecimento por meio do trabalho.

\section{O discurso do campo e o campo do discurso}

A transformação da "educação rural" em "educação do campo" é fenômeno relativamente recente, tendo por referência fundamental a primeira conferência nacional "Por uma Educação Básica do Campo", realizada em 1998 e organizada pelo MST, CNBB, UNICEF e UNESCO. Um histórico dessa transformação - que não perseguiremos aqui - encontra-se bem documentado em vários artigos, como Souza (2008) ou Silva (2006), e nas teses de Molina (2003) e de Freitas (2007).

O que é importante notar é que tal transformação vai na direção de anseios e objetivos da população que vive no campo, anunciando, como diz Caldart (2004), um movimento que, mais do que o direito de ser educado no lugar onde se vive, defende o direito a uma educação pensada a partir desse lugar e com sua participação, vinculada à cultura e às necessidades humanas e sociais da população do campo.

Na mesma linha, Fernandes (2006) defende espaço e território como categorias essenciais para pensar o campo: “[...] enquanto o agronegócio organiza o seu território para a produção de mercadorias, dando ênfase a esta dimensão territorial, o campesinato organiza o seu território para realização de sua existência [...]” (p. 29). A subordinação do campo à lógica econômica é reducionista, visto que esta é apenas uma dimensão da idéia de território.

O campo deve ser entendido como conjunção de territórios imateriais (produção de conhecimento, identidade, cultura) e territórios materiais (produção da vida e de seus meios). É a partir dessa compreensão alargada que se opera a passagem de uma educação rural para uma educação do campo. 
Mas essa operação responde também a outras e, talvez, mais importantes necessidades. No histórico da passagem de uma expressão à outra se tem, não apenas a construção de um novo conceito, mas a construção de um conceito que se quer contra-hegemônico para, opondo-se ao discurso liberal hegemônico de uma educação instrumental para o campo, tornar esse novo discurso hegemônico a seu turno. Tratase, na realidade, de uma luta pelo direito do campo dizer seu discurso sobre o campo e a Educação do Campo; trata-se, fundamentalmente, de uma luta de poder.

O que se busca, portanto, não é apenas dizer um discurso sobre a Educação do Campo, mas apoderar-se do discurso sobre ela, fazê-lo seu, e fazê-lo dominante.

Pode-se imaginar (e eu acrescentaria, ingenuamente) o embate de discursos sobre a Educação do Campo como um embate científico, no qual se apresentam e se discutem argumentos racionais e, à luz da racionalidade, se extraem o alcance e as limitações de cada posição. Pode-se imaginar, também (e acredito que avançaremos na discussão assim fazendo), o embate de discursos sobre a Educação do Campo como um embate político, no qual posições excluídas - de camponeses, de movimentos sociais, de acadêmicos e educadores - lutam para transformar a forma de conceber o campo.

Assim, tomar o discurso sobre a Educação do Campo representa um ato de afirmação identitária, na medida em que declara sua "permanente associação com as questões do desenvolvimento e do território no qual ela [a educação] se enraíza" (MOLINA, 2006, p. 10); um ato de afirmação política, na medida em que busca uma educação libertadora, voltada para a totalidade do ser humano; e, um ato de afirmação de poder, na medida em que se contrapõe ao processo hegemônico do capital.

O que nos traz esse discurso que o autoriza à posição de contra-hegemônico? De que exclusões ele é representante, que estariam rejeitadas pela razão instrumental liberal? Que neutralidade ele desafia, neutralidade que é estratégia de um viés dominante, mas dissimulado?

\section{As dimensões do discurso}

Esse discurso da Educação do Campo representa uma alternativa ao discurso neoliberal, uma luta contra a lógica instrumental capitalista, opondo à globalização homogeneizante a experiência vivida e o território.

Esse discurso nos fala de uma Educação do Campo com múltiplas dimensões, que desafiam, cada uma, a pseudo-neutralidade e a pseudo-universalidade do discurso educativo capitalista. A Educação do Campo estrutura-se como conceito para além da "dimensão escolar, reconhecendo e valorizando as diferentes dimensões formativas presentes nos processos de reprodução social nos quais estão envolvidos os sujeitos do campo [...]" (MOLINA; SÁ, 2010, p. 369).

Dessas múltiplas dimensões, a política é, certamente, a dominante. Nesse sentido, é paradigmática a proposta do Movimento dos Trabalhadores Rurais Sem Terra (MST). Trata-se de uma proposta contra-hegemônica, pois subverte a forma como a escola se organiza e a forma como a educação se relaciona com o movimento. 
Seus princípios pedagógicos são "o enfoque de classe, a autogestão, a conjugação do ensino com o trabalho produtivo e o estudante-trabalhador" (DAL RI; VIEITEZ, 2004, p. 55), que caracterizam claramente essa dimensão política que a Educação do Campo adquire. Tal dimensão está largamente exposta nos vários textos que trabalham a proposta pedagógica do MST (ver, por exemplo, CALDART, 2004; DAL RI; VIEITEZ, 2004; SOUZA, 2008). Não avançaremos nessa direção.

Interessa-nos aqui discutir três outras dimensões, menos exploradas na literatura, mas igualmente representativas de um projeto contra-hegemônico da Educação do Campo: a dimensão epistemológica, a dimensão sociológica, e a dimensão da formação.

\section{A dimensão Epistemológica}

Entendemos o conhecimento como construção social e histórica e a educação como vetor desse conhecimento. A educação é imprescindível ao ser humano visto que não nascemos suficientemente equipados (do ponto de vista genético) para a produção de nossa existência. Não se deve, no entanto, entender educação como mero transporte ou transmissão de conhecimento: ela é, também, produtora de conhecimento.

Do ponto de vista sócio-histórico, que tem em Vygotsky seu grande representante, o conhecimento é construído pelo indivíduo, mas as interações sociais têm papel de destaque nessa construção. Considera-se o trabalho como ação transformadora consciente da natureza e criador da cultura e da história. Da mesma forma, considera-se que é na interação com o mundo natural e social que o homem se constrói. No entanto, essa interação é mediada, isto é, a relação do homem com o mundo não é uma relação direta, mas uma relação com a intermediação de outros elementos (OLIVEIRA, 2004). Como diria Marx (2010, p. 128), "a natureza não está, nem objetiva nem subjetivamente, imediatamente disponível ao ser humano [...]”.

A história e a cultura do grupo são a matéria-prima que é apresentada ao indivíduo em sua interação com os outros para seu desenvolvimento psicológico. Entretanto, a cultura não é algo acabado, mas dinâmico e constantemente reconstruído. A internalização, pelo indivíduo, de elementos da cultura se dá na forma de reconstrução, que depende desde a história do grupo até a experiência vivida pelo indivíduo concreto.

Entendido dessa maneira, o conhecimento não se limita a sua forma científica, existindo também na forma filosófica, artística, mítico-religiosa e prático-cotidiana, esta última conhecida ainda como o conhecimento de senso comum.

Ocorre que a ciência, na modernidade, colonizou todas as outras formas de conhecimento, caracterizando uma "cientifização" do mundo e levando ao que Santos (2000) chama de concentração de energia emancipatória na ciência e na tecnologia. Emancipatória pois, pelo menos nos primórdios da modernidade, a racionalidade científica desafiou dogmas da Igreja e criticou as justificativas naturais para a hierarquia social, promovendo avanços em direção à liberdade e autonomia do ser humano. 
Entretanto, o desenvolvimento do capitalismo instrumentalizou a ciência moderna, que se tornou sua principal força produtiva. Domínio da ciência, domínio do mercado e desenvolvimento tecnológico (ciência convertida em força produtiva) são as condições que levaram ao processo histórico que transformou o impulso emancipatório da ciência em força de regulação a serviço do capitalismo.

Assim, o conhecimento tende a limitar-se duplamente: quanto a sua forma, dominada pela ciência; e quanto a seu uso, instrumentalizado pelo capitalismo.

O projeto da Educação do Campo se apresenta contra-hegemônico justamente por desafiar essas duas limitações. No primeiro caso, a Educação do Campo propõe o resgate do trabalho como produtor de conhecimento e dos saberes práticos como fonte ou origem de princípios pedagógicos. "Os professores sabem. Os alunos também sabem. Só que são saberes diferentes. É no coletivo da Escola que estes saberes são trocados. O resultado é um saber melhor para todos" (MST, 2005, p. 33).

O risco aqui é o de uma rejeição do conhecimento científico para dar lugar a uma valorização excessiva dos saberes práticos. Não se pode, como argumenta Oliveira (2008), abrir mão do conhecimento científico para o entendimento da realidade social. E esse autor continua (op. cit., 392), afirmando que a educação "[...] necessita da apropriação pelos indivíduos, e pelos trabalhadores em especial, do arcabouço científico-filosófico-cultural construído pela humanidade ao longo de sua história, a condição primeira para formar indivíduos livres".

O Campo se apropria do discurso da Educação ao contestar o discurso vigente, instrumentalizado e bancário, na expressão de Paulo Freire, e propor a construção conjunta do conhecimento - professor e aluno como aprendizes -, partindo de um saber ingênuo que supera sua própria ingenuidade (FREIRE, 1995).

É nesse movimento de contestação de uma educação bancária que a Educação do Campo enfrenta a segunda limitação do conhecimento: sua instrumentalização pelo capitalismo. Rejeitando uma educação instrumental construída pelo capital para a exploração do homem e da natureza, a Educação do Campo aponta para o conhecimento e a transformação da natureza para a liberdade e o bem-estar do ser humano.

\section{A dimensão sociológica}

Entendemos que a educação não é social ou ideologicamente neutra. Ela assumiu, na sociedade capitalista, a forma de invasão cultural, entendida como imposição de sistemas de valores por meio de relações autoritárias, ainda que dissimuladas. Nessa imposição de valores, o invasor esvazia o significado da cultura invadida, fratura suas características e a preenche com seus próprios valores culturais (RUBIO, 1997).

Essa invasão, no entanto, se dá de forma dissimulada. O invasor apresenta seus valores e seus produtos culturais como universais, como naturais e, porque não os pode apresentar como os únicos possíveis, os apresenta como os únicos válidos. É nesse sentido que Bourdieu nos apresenta o sistema escolar como legitimador do saber das classes dominantes, ao negar a possibilidade de existência de qualquer outra cultura válida/legítima: 
Um dos efeitos menos notados da escolaridade obrigatória é o fato de que ela consegue obter das classes dominadas um reconhecimento do saber e do saber-fazer legítimos (por exemplo, em termos de direito, de medicina, de técnica, de entretenimento ou de arte), resultando na desvalorização do saber e do saber-fazer que elas dominam de forma eficaz (por exemplo, o direito consuetudinário, a medicina doméstica, artesanato, entretenimento ou arte). (BOURDIEU; PASSERON, 1970, p. 57, tradução nossa).

A isso Bourdieu denomina violência simbólica, isto é, a imposição dissimulada de um arbitrário cultural (BOURDIEU; PASSERON, op. cit.).

Partindo do pressuposto de que culturas são incomensuráveis, isto é, de que não se pode objetivamente definir uma cultura como superior a outra, Bourdieu translada para a escola a ideia de que a cultura consagrada que ela transmite não seria superior a nenhuma outra. $\mathrm{O}$ valor dessa cultura transmitida seria arbitrário, apesar de socialmente reconhecida como legítima e universalmente válida.

Essa conversão de arbitrário em universal só se explica a partir da luta entre os vários arbitrários culturais, representativos dos vários grupos em disputa pela hegemonia na sociedade. A relação de força entre esses grupos define qual arbitrário cultural se imporá como legítimo diante dos outros (BOURDIEU, 1987).

Bourdieu alerta, entretanto, que essa legitimidade só pode ser obtida se o caráter de arbitrariedade e de imposição for dissimulado. A cultura dominante deve ser apresentada como "a cultura", universal, neutra, válida e, em princípio, acessível a todos por meio da educação escolar. Para obter esse efeito, basta que a escola negue as diferenças entre seus diversos públicos, tratando formalmente de modo igual os desiguais. Como diz Bourdieu (1998, p. 53), "[...] para que sejam favorecidos os mais favorecidos e desfavorecidos os mais desfavorecidos, é necessário e suficiente que a escola ignore [...] as desigualdades culturais entre crianças das diferentes classes sociais". Esse tratamento pseudo-igualitário privilegia aqueles que, socializados nos padrões da classe dominante, apresentam conhecimentos lingüísticos e culturais, e mesmo comportamentos, alinhados com os que a escola define como "corretos".

Assim, ao transpor para o campo os modos da cidade, ao treinar os docentes nos padrões culturais da classe dominante, ao valorizar um determinado arbitrário cultural em detrimento de outras formas de cultura e conhecimento, o sistema educacional automaticamente reproduz as desigualdades sociais e exclui os povos do campo. O que o campo sabe não tem valor de conhecimento; o que o campo produz não tem valor de cultura; o que o campo é não tem valor de existência. Essa segregação tem por objetivo, nas palavras de Arroyo,

[...] perpetuar uma das funções da autoidentidade das teorias pedagócias hegemônicas: ignorar os saberes, valores, culturas, modos de pensar e de se afirmar e humanizar dos povos colonizados, dos trabalhadores para, reafirmando sua inferiorização, afirmar a função da pedagogia de trazê-los para a cultura e o conhecimento legítimos, para a civilização e a maioridade. (ARROYO, 2012, p. 30). 
Uma proposta de Educação do Campo deve subverter essa lógica e apresentar seu discurso, sua cultura, seu conhecimento como válidos e legítimos. Essa proposta deve rever as bases da pedagogia oficial e recusar as categorias com que esta caracteriza os povos do campo. No dizer de Arroyo (op. cit., p. 40), deve recusar os rótulos de "marginalizados, excluidos, desiguais, inconscientes" (grifos no original). Ao aceitar esses rótulos, a proposta reforçaria a lógica oficial, aceitando o arbitrário cultural dominante e anunciando que buscaria trazer esses "marginalizados, excluídos, desiguais, inconscientes" para dentro do padrão cultural corrente.

Um proposta contra-hegemônica de Educação do Campo nega, de princípio, a lógica dominante. Não recusa o conhecimento técnico-científico acumulado, mas rejeita sua apropriação acrítica; não recusa a cultura existente, mas afirma sua dinamicidade e seu direito de participar de sua construção; não recusa a história, mas declara sua participação nela. Em outras palavras, essa proposta de Educação do Campo defende uma educação construída pelos povos do campo, para os povos do campo, com o saber dos povos do campo. É uma educação que tem os povos do campo como sujeitos.

\section{A dimensão da formação}

Entendemos que formar é construir conhecimentos, buscando desenvolver a personalidade global e articulando teoria e prática. Mas o formar não ocorre em um vácuo político e a formação insere-se em um projeto de sociedade. Pode ser uma formação instrumental, direcionada ao mercado de trabalho. Pode ser uma formação idealista, desvinculada da práxis real. Pode, também, ser uma formação do ser humano na sua totalidade social.

Um projeto de Educação do Campo deve basear-se no tripé: o trabalho como princípio educativo; as relações/tensões entre o conhecimento tradicional e o conhecimento técnico-científico; a interdisciplinaridade na educação (MENEZES NETO, 2011).

\section{a) O trabalho como princípio educativo}

O sujeito se constitui nas relações com os outros, relações estas que são mediadas por meios técnicos ou simbólicos. Do ponto de vista da filogênese existe um mundo material que antecede a existência do homem. Entretanto, a ação do homem sobre o mundo o transforma, não apenas no sentido material, mas também no sentido simbólico. A ação do homem dá significado ao mundo e esta é a maneira pela qual o homem se apropria do mundo.

Da mesma forma, do ponto de vista da ontogênese, é nas relações sociais que se estabelecem que o indivíduo se apropria da cultura de seu grupo. Essa cultura (que é fundamentalmente um mundo simbólico) pré-existe ao indivíduo, no mesmo sentido de que o mundo material antecede o homem. $\mathrm{O}$ indivíduo nasce em um meio cultural repleto de significações social e historicamente produzidas, que são apropriadas e ressignificadas pelo sujeito ao longo de suas relações. 
A abordagem sócio-histórica vê o trabalho como transformador da natureza e criador da cultura e da história. Da mesma forma, considera que é na interação com o mundo natural e social que o homem se constrói.

Assim, a história e a cultura do grupo são a matéria-prima que é apresentada ao indivíduo em sua interação com os outros. Essa é a matéria-prima para o desenvolvimento psicológico do indivíduo. Entretanto, a cultura não é algo acabado, mas algo dinâmico e constantemente reconstruído. A internalização, pelo indivíduo, de elementos da cultura se dá na forma de reconstrução, que depende tanto da história do grupo quanto da experiência vivida pelo indivíduo concreto.

Também a educação - vista como apropriação/reconstrução da cultura do grupo - tem seu princípio na ação humana. A formação humana global, que tem suas raízes na compreensão das relações sociais, culturais, científicas e práticas do mundo, situa o conhecimento no mundo material da produção humana (MENEZES NETO, 2011).

O trabalho, como ação do homem sobre o mundo, produz os meios de existência, a cultura e o conhecimento. É nesse sentido que o trabalho se apresenta como princípio educativo. Ainda que as formas históricas assumidas pelo trabalho possam ser degradantes e alienantes, o trabalho nunca será pura negatividade, sempre havendo espaço para criar e superar as formas de dominação e exploração. Mesmo nas formas extremas de dominação, como nas relações senhor-escravo, nas quais a humanidade do escravo não é reconhecida, ela não deixa de existir e de criar realidade humana (FRIGOTTO, CIAVATTA, 2012).

\section{b) O conhecimento tradicional e o conhecimento técnico-científico}

A articulação entre as formas de conhecimento tradicional e técnico-científico é um aspecto específico da tensão teoria-prática, que se materializa na tese de que a experiência de quem aprende deve ser o ponto de partida e o ponto de chegada dos processos de aprendizagem. Este é o fundamento de "todo o ensino partindo da prática”, presente nos princípios pedagógicos do Movimento dos Trabalhadores $\mathrm{Ru}$ rais Sem Terra - MST. Ao mesmo tempo, fundamentar o conhecimento técnico-científico no cotidiano torna-se uma tarefa cada vez mais árdua a partir de certos limites (ARNAY, 1997). Trata-se de pressupostos/diretivas não triviais de serem conciliados, traduzindo-se em uma tensão entre o pólo do conhecimento científico e o pólo do conhecimento prático tradicional.

A discussão sobre a primazia da teoria sobre a prática, ou vice-versa, é uma das oposições ou antinomias há muito identificadas que permeiam a organização do pensamento filosófico e do senso comum (MARKOVÁ, 2006). Talvez a representação alegórica mais conhecida dessa oposição seja o fresco do pintor renascentista italiano Rafael - A Escola de Atenas - mostrando o filósofo Platão que aponta para o alto, para as coisas eternas e etéreas (representação alegórica da teoria) e o filósofo Aristóteles que, ao mesmo tempo, aponta para baixo, para o que é concreto (representação alegórica da prática). 
A literatura sobre educação discute e critica essa separação, apontando para o obstáculo que ela representa ao trabalho docente e propondo formas de sua superação (ver, por exemplo, FRANCO, 2008; NUNES, 2008; ALEXANDRE, 2011; CARVALHO, 2011; CRUZ, 2012).

Sem dúvida, a derivação direta de propostas de uma prática educativa a partir de sistemas teóricos abstratos não se sustenta, como bem demonstrou Carvalho (2011). O que resulta nessas circunstâncias é uma concepção tecnicista da prática, uma concepção não reflexiva, que a vê como um treinamento para realizar tarefas de uma determinada forma (FRANCO, 2008). A prática de caráter formador, em oposição à tecnicista, é aquela que permite a construção de um fazer significativo, uma prática crítica do saber instituído.

No entanto, a situação oposta, ou seja, a prática como pura empiria, centralizada exclusivamente na experiência imediata restringe as perspectivas do processo de transformação do ensino e da escola, podendo levar à omissão de variáveis de contexto no qual o próprio docente e os alunos estão inseridos (CRUZ, 2008).

Se é fato que a educação é uma atividade que foi praticada muito antes de sobre ela se teorizar e produzir conhecimento (ROLDÃO, 2007), é também certo que a teorização dessa prática, que se seguiu, gerou um corpo de conhecimentos que, ao interagir com a prática, a alimenta e transforma, retomando-se o ciclo. Trata-se a prática, portanto, de prática refletida, teorizada, crítica, caso contrário essa prática tende ao tecnicismo simplista, ao "aplicacionismo" de receitas pré-definidas.

Essa relação teoria-prática, interativa, de caráter formador, própria de um fazer significativo que reflete sobre si mesmo, é aquela que se encontra consignada na literatura especializada sobre a educação e nas teorias críticas; é aquela que se propõe como libertadora, como construtora de sujeitos.

\section{c) A interdisciplinaridade na educação}

A formação deve ser discutida em sua complexidade, adotando-se uma postura francamente anti-reducionista, recusando a compreensão do complexo a partir de sua fragmentação em elementos mais simples. É fundamental afrontar a complexidade enquanto tal.

Isso não significa abandonar o estudo aprofundado de partes ou dimensões de um fenômeno complexo. Entretanto, também não significa limitar-se a esse estudo, acreditando que a soma cumulativa dos conhecimentos gerados reconstitua "naturalmente" a compreensão do todo. A irredutibilidade do objeto complexo que é a formação exige uma postura interdisciplinar para sua compreensão.

Essa postura apresenta-se na inter-relação da atividade política e da construção da subjetividade na prática formativa. A interdisciplinaridade manifesta-se, também, na proposta de diálogo não apenas de diferentes saberes científicos, mas de diferentes formas de saber. Para isso, trabalha-se a construção de conhecimento baseada na alternância e no cruzamento de três tipos de saberes: os saberes da experiência 
dos que vivem uma dada realidade; os saberes da ação daqueles que se engajam com os primeiros, e os saberes científicos propriamente ditos. Essa abordagem permite tanto o trabalho com problemas reais específicos de uma comunidade, quanto a construção de conhecimento científico e, finalmente, a formação de indivíduos atuantes no processo.

Essa é a visão de Paulo Freire (FREIRE, 1995, p. 6) quando propõe que "é preciso que o educando se assuma ingenuamente para, assumindo-se ingenuamente, ultrapassar a ingenuidade". A formação deve, assim, partir do conhecimento produzido pela prática do campo e atingir maior rigor, que reconstrua esse conhecimento.

\section{Considerações finais}

A Educação do Campo resulta de um novo projeto de sociedade, baseado no conhecimento e na transformação e preservação da natureza para o desenvolvimento integral do ser humano, buscando sua emancipação e autonomia. Representa, portanto, mais do que uma alternativa ao modelo capitalista de produção, uma proposta contra-hegemônica para a sociedade.

No embate para se apoderar do discurso sobre o campo, a Educação do Campo oferece uma proposta ampla e articulada, embora não isenta de contradições em suas realizações concretas. Tendo como fundamento e princípio o trabalho, a Educação do Campo desdobra-se em diferentes dimensões, para além da própria dimensão pedagógica, e vai além de sua forma escolar institucionalizada.

Contestando a raiz mesma da construção do conhecimento dentro do capitalismo, a Educação do Campo contrapõe-se ao uma ciência instrumentalizada - cujo exemplo acabado é a máquina, que representa a objetivação das funções intelectuais e científicas no processo produtivo. Contrapõe-se a uma ciência neutra, na qual a tarefa de obter conhecimento sobre o mundo se dá a partir de indivíduos solitários e não de membros de grupos historicamente constituídos. Contrapõe-se a uma ciência absoluta, que exclui todas as demais formas de conhecimento do mundo.

A Educação do Campo afirma o direito dos povos do campo a pensar e a definir a educação a partir de seu lugar, de sua cultura e de suas necessidades. Em outras palavras, afirma os povos do campo como sujeitos da educação.

\section{Referências}

ALEXANDRE, A. F. Pesquisa acadêmica e prática educativa como um problema sociológico. Cadernos de Pesquisa, São Paulo, v. 41, n. 143, p. 502-515, 2011.

ARNAY, J. Reflexões para um debate sobre a construção do conhecimento na escola: rumo a uma cultura científica escolar. In: ARNAY, J.; RODRIGO, M. J. (Orgs.). A construção do conhecimento escolar. São Paulo: Ática, 1997. p. 32-47.

ARROYO, M. G. Outros sujeitos, outras pedagogias. Petrópolis: Vozes, 2012.

BAUMAN, Z. A sociedade individualizada. Vidas contadas e histórias vividas. Rio de Janeiro: Zahar, 2009.

BOUND, K. Brazil the natural knowledge economy. London: Demos, 2008. 
BOURDIEU, P. Escritos de educação. Petrópolis: Vozes, 1998.

. Choses dites. Paris: Les Editions du Minuit, 1987.

BOURDIEU, P.; PASSERON, J-C. La reproduction. Paris: Les Editions du Minuit, 1970.

BRASIL. Resolução CNE/CEB n. 1, de 3 de abril de 2002. Institui as diretrizes operacionais para a educação básica nas escolas do campo. Diário Oficial da União, Brasília: 9 de abril de 2002. Seção 1, p. 32.

. Lei no 13.005, de 25 de junho de 2014. Aprova o Plano Nacional de Educação para o decênio 2011-2020, e dá outras providências. Disponível em: <http://www.planalto.gov.br/ ccivil_03/_Ato2011-2014/2014/Lei/L13005.htm>. Acesso em: 11 maio 2015.

CALDART, R. Pedagogia do Movimento Sem Terra. Petrópolis: Vozes, 2004.

CARVALHO, J. S. F. A teoria na prática é outra? Considerações sobre as relações entre teoria e prática em discursos educacionais. Revista Brasileira de Educação, v. 16, n. 47, p. 307-322, 2011.

CRUZ, G. B. Teoria e prática no discurso de pedagogia. Educação e Pesquisa, São Paulo, v. 38, n. 1, p. 149-164, 2012.

DALRI, N. M.; VIEITEZ, C. G. A educação do movimento dos sem-terra. Revista Brasileira de Educação, n. 26, maio/ago., 2004. p. 44-57.

FERNANDES, B.M. Os campos da pesquisa em educação do campo: espaço e território como categorias essenciais. In: MOLINA, M. C. (Org.). Educação do campo e pesquisa. Questões para reflexão. Brasília: Ministério do Desenvolvimento Agrário, 2006. p. 27-39.

FRANCO, M. A. S. Entre a lógica da formação e a lógica das práticas: a mediação dos saberes pedagógicos. Educação e Pesquisa, São Paulo, v. 34, n. 1, p. 109-126, 2008.

FREITAS, H. C. A. A construção da rede sócio-técnica de educação de assentados da reforma agrária: o PRONERA. Tese (Doutorado em Sociologia Política), Centro de Filosofia e Ciências Humanas, Universidade Federal de Santa Catarina, Florianópolis, 2007.

FRIGOTTO, G.; CIAVATTA, M. Trabalho como princípio educativo. In: CALDART, R. S.; et al. (Orgs.). Dicionário da Educação do Campo. Rio de Janeiro, São Paulo: Escola Politécnica de Saúde Joaquim Venâncio, expressão popular, 2012. p. 748-755.

MARKOVÁ, I. Dialogicidade e representações sociais. As dinâmicas da mente. Petrópolis: Vozes, 2006.

MARX, K. Manuscritos econômico-filosóficos. São Paulo: Boitempo, 2010.

MENEZES NETO, A. J. Formação de professores para a educação do campo: projetos sociais em disputa. In: ANTUNES-ROÇHA, M. I.; MARTINS, A. A. (Orgs.). Educação do Campo. Desafios para a formação de professores. 2. ed. Belo Horizonte: Autêntica, 2011. p. 25-38.

MOLINA, M. C. A contribuição do PRONERA na construção de políticas públicas de educação do campo e desenvolvimento sustentável. Tese (Doutorado em Desenvolvimento Sustentável), Centro de Desenvolvimento Sustentável, Universidade de Brasília, Brasília, 2003.

. Introdução. In: MOLINA, M. C. (Org.). Educação do campo e pesquisa. Questões para reflexão. Brasília, DF: Ministério do Desenvolvimento Agrário, 2006. p. 9-14.

MOLINA, M. C.; SÁ, L. M. Desafios e perspectivas na formação de educadores: reflexões a partir da licenciatura em educação do campo da Universidade de Brasília. In: SOARES, L. et al. Convergências e tensões no campo da formação e do trabalho docente. v. 2. Belo Horizonte: Autêntica, 2010. p. 369-388. 
MST. Dossiê MST ESCOLA: documentos e estudos, 1990-2001. São Paulo: Expressão Popular, Setor de Educação do MST/Iterra, 2005.

NUNES, D. R. P. Teoria, pesquisa e prática em educação: a formação do professor-pesquisador. Educação e Pesquisa, São Paulo, v. 34, n. 1, p. 97-107, 2008.

OLIVEIRA, M. A. As bases filosóficas e epistemológicas de alguns projetos de educação do campo: do pretendido marxismo à aproximação ao ecletismo pós-moderno. Tese (Doutorado em Educação), Universidade Federal do Paraná, Curitiba: 2008.

OLIVEIRA, M. K. Vygostky. Aprendizado e desenvolvimento. Um processo sócio-histórico. 4. ed. São Paulo: Scipione, 2004.

ROLDÃO, M. C. Função docente: natureza e construção do conhecimento profissional. Revista Brasileira de Educação, v. 12, n. 34, p. 94-181, 2007.

RUBIO, E. M. Freire: consciência e libertação (a pedagogia perigosa). Revista da Faculdade de Educação, v. 23, n. 1-2, p. 1-4, jan./dez. 1997.

SANTOS, B. S. A crítica da razão indolente. Contra o desperdício da experiência. v. 1: para um novo senso comum: a ciência, o direito e a política na transição paradigmática. São Paulo: Cortez, 2000.

SILVA, M. S. Da raiz à flor: produção pedagógica dos movimentos sociais e a escola do campo. In: MOLINA, M. C. (Org.). Educação do campo e pesquisa. Questões para reflexão. Brasília: Ministério do Desenvolvimento Agrário, 2006. p. 60-93.

SILVA, L. H.; COSTA, V. A.; ROSA, W. M. A educação de jovens e adultos em áreas de reforma agrária: desafios da formação de educadores do campo. Revista Brasileira de Educação, v. 16, n. 46, p. 149-270, jan./abr. 2011.

SOUZA, M. A. Educação do campo: políticas, práticas pedagógicas e produção científica. Educação e Sociedade, Campinas, v. 29, n. 105, p. 1089-1111, set./dez. 2008.

\section{Nota}

${ }^{1}$ Este trabalho contou com o apoio financeiro do $\mathrm{CNPq}$, na forma de bolsa de pesquisa e apoio a projeto.

* Professora doutora da Universidade de Taubaté, Taubaté, São Paulo, Brasil.

\section{Correspondência}

Edna Maria Querido de Oliveira Chamon - Universidade de Taubaté, Departamento de Economia Contabilidade e Administração. Rua Expedicionário Ernesto Pereira, s/n, Portão 3, Centro. CEP: 12030-320, Taubaté, São Paulo - Brasil.

E-mail: edna.chamon@gmail.com

Recebido em 11 de maio de 2015

Aprovado em 11 de novembro de 2015 
